\title{
Políticas Nacionais e Implementação Subnacional: Uma Revisão da Descentralização Pós-Fundef*
}

\author{
Sandra Gomes
}

\section{INTRODUÇÃO}

\begin{abstract}
aprovação e a implementação recente do Fundo de Manutenção e A Desenvolvimento da Educação Básica e de Valorização dos Profissionais da Educação (Fundeb), em 2007 e em 2008, respectivamente, são entendidas pelos analistas das relações intergovernamentais como exemplo de um conjunto amplo de estratégias adotadas pelo governo federal brasileiro, a partir de meados da década de 1990, que promovem a coordenação de ações dos governos subnacionais (Arretche, 2005; 2007; Melo, 2005; Abrucio; 2005; Castro, Barreto e Corbucci, 2000). O desenho institucional do Fundeb - uma política de gestão dos recursos para a educação proposta pelo governo federal - foi baseado em uma medida anterior, em vigor até 2006, o Fundef (Fundo de Manutenção e Desenvolvimento do Ensino Fundamental e de Valorização do Magistério), aprovado em 1996 e implementado nacionalmente a partir de 1998. A diferença essencial entre uma norma e outra está na am-
\end{abstract}

\footnotetext{
* Parte dos argumentos deste artigo foi apresentada no VI Encontro da Associação Brasileira de Ciência Política (ABCP) em 2008. Agradeço à Telma Menicucci, comentadora da sessão temática, as sugestões feitas na ocasião. Este artigo também se beneficiou dos comentários e das sugestões valiosas de Marta Arretche, José Roberto Rus Perez, Haroldo Torres, Eduardo Marques, Fernando Limongi, Julia Andrade, Maria de Lourdes Fonseca, Gabriel Feltran, Encarnación Moya e Alexandre Barbosa. Agradeço a todos.

DADOS - Revista de Ciências Sociais, Rio de Janeiro, Vol. 52, nº3, 2009, pp. 659 a 690.
} 
plitude: o Fundeb trata de toda a educação básica, ao passo que o Fundef se aplicava apenas ao ensino fundamental.

Em comum, destacam-se três objetivos centrais. Em primeiro lugar, criar incentivos para que os governos subnacionais aumentem a oferta de vagas escolares, ampliando o acesso de crianças e de jovens à escola. Em segundo, efetivar uma redistribuição dos recursos que estão constitucionalmente atrelados à educação para que os governos subnacionais passem a ser, pelo menos parcialmente, remunerados de acordo com o serviço efetivamente prestado, ou seja, com o número de alunos atendidos. Por fim, garantir a aplicação mínima de recursos do fundo $(60 \%)$ na remuneração do magistério em efetivo exercício.

Implicitamente, os atores políticos envolvidos na proposição e na apreciação do Fundeb reconhecem que o Fundef foi um modelo institucional que gerou incentivos positivos com relação à provisão de serviços educacionais, ou seja, alterou os cálculos dos governantes e despertou o interesse destes em assumir a oferta do ensino fundamental. A lógica de incentivos (e de constrangimentos) ao comportamento dos governos subnacionais funcionaria de forma relativamente simples e quase mecânica: ao atrelar atendimento de alunos a recursos fiscais, os governos seriam induzidos a aumentar seus serviços educacionais.

É também consensual entre analistas dos impactos do Fundef (Neubauer, 1999; Costa, 1998; Castro, Barreto e Corbucci, 2000; Semeghini, 2001; Pinto, 2002; Rodriguez, 2001; Ribeiro, 2002; Laczynski, 2004; Abrucio, 2005; Arelaro, 2005; Arretche, 2005; Melo, 2005; Souza, 2005; Castro e Duarte, 2008) que esse fundo é o fator explicativo do aumento de matrículas no ensino fundamental pelos municípios. De acordo com essas interpretações, o Fundef teria despertado o interesse dos municípios com relação à provisão de vagas nesse nível de ensino. Com a aplicação desse desenho institucional ao Fundeb, agora estendido para toda a educação básica, espera-se que os resultados sejam similares: aumento na oferta de vagas nas áreas de competência dos municípios (creche e pré-escola) e dos governos estaduais (ensino médio).

De fato, no primeiro ano de implementação nacional do Fundef, o crescimento das matrículas no ensino fundamental pelos municípios brasileiros foi significativo: 21,5\% (1997/1998). Análises preliminares do primeiro ano de instauração do Fundeb também sugerem um crescimento na oferta de vagas. Por exemplo, nas creches municipais do Brasil, houve uma variação positiva nas matrículas: 8,7\% entre 2007 e 
2008. A diferença entre esses dois exemplos, no entanto, é que o intenso crescimento das matrículas no ensino fundamental não é apenas resultado do interesse dos municípios em ampliar suas vagas, como procuro argumentar neste artigo.

Apesar da importância da aprovação da norma federal do Fundef, que de fato alterou os cálculos dos atores políticos, há outros fatores relevantes que explicam a decisão dos governos subnacionais em expandir ou não seus sistemas de ensino. Além disso, há razões para questionar a tese de que o desenho institucional do Fundeb vai gerar efeitos similares aos verificados com a implementação do Fundef, já que o ensino fundamental tem uma característica praticamente ausente no restante da educação básica: é um serviço de responsabilidade compartilhada entre o governo do estado e seus municípios.

Como veremos adiante, o crescimento da oferta de vagas no caso do ensino fundamental pelos municípios, após a instauração nacional do Fundef, não foi uniforme em todo o país. No caso desse nível de ensino, o interesse dos governos estaduais em transferir o atendimento para seus municípios é central para explicar o resultado dessa política.

Em boa medida, as análises que atribuem exclusivamente ao Fundef o crescimento das matrículas são uma resposta do interesse acadêmico em compreender as estratégias disponíveis ao governo federal para produzir coordenação nacional em um estado federativo, ou seja, em compreender como ocorre a aprovação de normas que interferem diretamente na autonomia administrativa e decisória dos governos subnacionais. Contudo, do ponto de vista da implementação ou da execução efetiva de medidas aprovadas na esfera federal, tais normas podem ou não produzir efeitos universais - de forma mecânica ou quase automática, como a descrita pelos estudos da área - para todos os governos subnacionais. Em meu entendimento, baseado em uma revisão desses estudos e dos efeitos gerados pelo Fundef, há duas distinções analíticas relevantes para compreender o alcance de medidas de coordenação nacional: as normas de efeito imediato, que produzem os efeitos quase mecânicos, como os descritos pelos estudos das áreas; e as dependentes de adesão dos governos, em que outros fatores, além da norma federal aprovada, influenciam a decisão dos governos e, portanto, não necessariamente produzem resultados homogêneos. $O$ caso da emenda constitucional do Fundef é de interesse analítico, pois contém elementos desses dois tipos de norma. 
O diagnóstico que apresento aqui sugere que a norma aprovada pelo governo federal - o Fundef - não pode ser o único mecanismo explicativo do rápido crescimento das matrículas municipais no ensino fundamental, mas é explicativo dos efeitos imediatos gerados nos orçamentos municipais e estaduais com relação à compulsoriedade de gastos.

No que diz respeito especificamente aos incentivos do Fundef à municipalização do ensino, os próprios argumentos lógicos apresentados para justificar o interesse que seria despertado nos governos municipais também não são suficientes para explicar por que ocorreu o crescimento das matrículas municipais, e não o das estaduais. Isso porque, dado que o ensino fundamental é uma responsabilidade compartilhada entre estados e municípios, não havia nada no desenho institucional do Fundef que impedisse os governos estaduais de também adotar a estratégia de ampliar suas redes de ensino e, assim, aumentar suas receitas. Por que mesmo assim assistimos ao crescimento da municipalização do ensino, e não a uma estadualização das matrículas?

Minha resposta a essa pergunta indica que, para compreendermos esse movimento, precisamos levar em consideração os interesses dos governos estaduais naquele contexto, inclusive como indutores também da municipalização do ensino em seus estados. Além disso, as interpretações correntes atribuem um peso muito grande ao incremento de receitas que seria gerado ao se ampliar a oferta de serviços, mas pouca atenção tem sido dispensada aos custos envolvidos na administração e no custeio de novos serviços públicos.

Neste artigo, analiso a forma de crescimento das matrículas no ensino fundamental - uma medida que compreendo como dependente de adesão dos governos subnacionais - nos estados da federação, após a implementação do Fundef, destacando um novo elemento explicativo: os governos de estado. Isso significa que uma parte considerável do crescimento das redes municipais é explicada pela transferência de vagas das redes estaduais, e não de iniciativas autônomas dos municípios derivadas exclusivamente dos incentivos embutidos na legislação federal.

O presente artigo está dividido em três seções, além da conclusão. Na primeira parte, apresento uma síntese das principais estratégias de coordenação nacional utilizadas pelo governo federal no período pós-constituinte discutidas nos estudos da área. Com base nesses estudos, 
é possível propor que, em termos de implementação de políticas, uma distinção analítica relevante para compreender os efeitos dessas diferentes estratégias nos resultados das políticas se encontra entre as medidas de efeito imediato e as dependentes de adesão dos governos. $\mathrm{Na}$ segunda parte, apresento alguns aspectos do Fundef, com ênfase nas medidas que geraram efeitos imediatos e naquelas dependentes de adesão (nesse último caso, a descentralização do ensino). Nessa seção também é discutida a racionalidade que os atores políticos, nas esferas municipais de governo, teriam com base nos incentivos da legislação federal. Na terceira parte, demonstro, empiricamente, a evolução das matrículas no ensino fundamental por estado da federação. Pelo menos no caso dessa política, o papel dos governos estaduais é central para explicar os diferentes níveis de municipalização nos estados. Por fim, as principais conclusões são retomadas.

\section{CAPACIDADE DE COORDENAÇÃO NACIONAL DO GOVERNO FEDERAL: BREVE SUMÁRIO DOS ESTUDOS RECENTES}

A literatura que trata da capacidade dos governos de produzir políticas nacionais esteve fortemente influenciada pelos estudos que apontavam a forma de estado (federativo ou unitário) como uma variável explicativa dos resultados das políticas. No início desse debate, defendia-se que, nos estados federativos, a capacidade de produção de políticas de alcance nacional seria mais limitada, dado o poder de veto e/ou a independência política das instâncias subnacionais de governo, que tenderiam a dificultar ou fragmentar as ações governamentais (para uma revisão extensa dessa literatura, ver Arretche, 2007).

No entanto, estudos recentes sobre o efeito da forma de estado têm questionado o poder dessa variável para explicar a capacidade de produção de políticas nacionais (Obinger, Liebfried e Castles, 2005; Arretche, 2007; Arretche, Vazquez e Gomes, no prelo). A observação empírica das formas de interação entre o governo central e seus entes subnacionais, em diferentes países, revela um quadro de variadas combinações institucionais que produzem maior ou menor autonomia para os governos locais ou regionais, assim como maior ou menor supervisão nacional pelo governo central, tanto em estados federados quanto em unitários (Stegarescu, 2005; Sellers e Lidström, 2007). Ao contrário da premissa assumida por alguns estudos (Lijphart, 1999; Weaver e Rockman, 1993), federalismo não equivale, sempre e necessariamente, a uma menor capacidade de controle e de coordenação do 
governo central ou, ao contrário, a uma total autonomia ou liberdade de ação por parte dos governos subnacionais.

Com relação ao caso brasileiro, os estudos apontam que o Executivo federal tem feito uso de uma série de instrumentos institucionais que compensam os potenciais efeitos de dispersão que poderiam ser deduzidos com base na forma de estado (Abrucio, 2005; Melo, 2005; Arretche, 2007; Arretche, Vazquez e Gomes, no prelo). De maneira sintética, esses estudos apontam três tipos de diretrizes nacionais que têm sido utilizados pelo governo central: 1) normas que restringem a liberdade de gasto dos governos subnacionais; 2 ) normas que definem responsabilidades ou competências dos entes da federação com relação à provisão e à gestão de determinadas políticas públicas; ou 3) normas que criam incentivos para que os governos subnacionais passem a assumir a responsabilidade de prover políticas, especialmente as de cunho social. Essas diretrizes são instrumentos que objetivam produzir um ordenamento nacional na provisão dos serviços públicos. A contrapartida necessária é a diminuição da autonomia decisória dos governos subnacionais com relação às formas de alocação de recursos públicos e/ou de prioridades de políticas.

Os exemplos do primeiro tipo de regra são as obrigações de gastos mínimos em educação e saúde, e de gastos máximos com pessoal, limite de endividamento etc., que introduzem restrições à autonomia de gastos dos governos subnacionais. Assim, em qualquer cidade em que um cidadão residir no Brasil hoje, por exemplo, os governos estaduais e municipais têm a obrigação de gastar $25 \%$ de suas receitas orçamentárias em educação, independentemente das preferências dos governos, da clivagem ideológica dos partidos no poder ou mesmo do eleitorado.

As normas de segundo tipo referem-se à definição legal de competências entre níveis de governo; por exemplo, qual ou quais entes federados serão responsáveis pela oferta dos serviços de saúde, pelas políticas de assistência social, educação, saneamento, habitação etc. Muitas dessas definições foram estabelecidas na Constituição de 1988 ou até mesmo antes, ainda que um conjunto significativo de responsabilidades seja compartilhado entre diferentes níveis de governo, o que pressupõe medidas de ação coletiva ou coordenação para a provisão eficiente dos serviços. Essa sobreposição de responsabilidade tem também sido objeto de disputa judicial, como é o caso da expedição de licenças ambientais. Os autores dessas ações questionam a competência de mu- 
nicípios ou estados em expedi-las - em vez do órgão ambiental federal -, já que a Constituição é ambígua com relação a essa definição. Outra crítica comum à Constituição de 1988 era que o ordenamento ali estabelecido havia garantido mais recursos fiscais para os governos subnacionais, especialmente para os municípios, que responsabilidades efetivas na provisão dos serviços (Maluf e Souza, 1999; Almeida e Carneiro, 2003). Assim, o aprendizado histórico desse tipo de instrumento é que a simples definição desses marcos legais não é suficiente para garantir a provisão dos serviços pelos governos subnacionais.

Por esse motivo, a partir de meados dos anos 1990, o governo federal passou a criar políticas que embutiam incentivos para induzir os governos na provisão de serviços, normalmente atrelando repasses de recursos - ou o financiamento parcial dos serviços - ao cumprimento de contrapartidas estabelecidas pelo próprio governo. O caso da política nacional de saúde, o SUS (Sistema Único de Saúde), talvez seja o mais emblemático dessa estratégia construída ao longo da década de 1990, com a transferência de recursos pelo governo federal e contrapartidas de atendimento e, mais recentemente, de metas a alcançar - Pacto pela Saúde (Oliveira, 2007). Essa estratégia corresponde ao terceiro tipo de diretriz nacional que pode ser utilizado pelo Executivo federal. Então, essa forma de promover coordenação nacional é, em boa medida, resultado do reconhecimento da insuficiência da mera definição legal de competências.

Com base nesses três tipos de diretrizes que têm sido utilizados pelo governo federal brasileiro, de acordo com os estudos da área, é possível propor a seguinte distinção analítica: podemos esperar efeitos diferentes no resultado das políticas, dependendo da natureza da medida, se de efeito imediato ou dependente da ação ou da adesão dos governos subnacionais.

As medidas de efeito imediato referem-se às regulamentações que entram em vigor imediatamente após sua aprovação, são válidas para todo o conjunto de governos subnacionais a que tal norma diga respeito e limitam a autonomia decisória e/ou de alocação de recursos desses governos, ensejando patamares (mínimos ou máximos) nacionais. Para isso, o Executivo federal precisa apenas de apoio no Congresso para aprovação legislativa, seja a emenda constitucional, seja a infraconstitucional (como leis ordinárias ou complementares). Com a aprovação, todos os entes passam a ter de cumprir tal determinação. 
Aqueles que não o fizerem estarão sujeitos às penalidades da lei. Os Tribunais de Conta, assim como os conselhos municipais e estaduais de fiscalização do Fundef, por exemplo, passaram a ter a responsabilidade de verificar a efetiva aplicação dos recursos previstos na lei. Essas medidas são, portanto, as regras de primeiro tipo, como discutidas pela literatura; são as que definem patamares mínimos ou máximos de gastos e outras obrigações.

Por outro lado, existem normas aprovadas pelo Executivo federal que não têm efeito imediato, pois dependem da decisão dos governos subnacionais em implementar tais políticas. As regras de definição de competências legais com relação às responsabilidades de provisão de serviços, como discutido acima, não tiveram - pelo menos no caso brasileiro - efeito imediato, porque a simples definição legal não gerou a ação dos governos subnacionais. Da mesma maneira, as regras de incentivo à provisão seriam caracterizadas por um desenho institucional que embute incentivos para a ação dos governos subnacionais, mas não os obriga a adotar tais políticas. Nesses casos, ou seja, na implementação efetiva das políticas, não necessariamente observaremos um comportamento homogêneo em todos os governos.

A causa da adoção de uma ou de outra diretriz pelo governo federal está relacionada ao legado histórico das políticas no momento da formulação, aos aprendizados de políticas anteriores e às dificuldades operacionais, ou mesmo políticas, de decretar nacionalmente um novo padrão de atribuição de responsabilidades. No caso do incentivo à municipalização do ensino fundamental contida no Fundef, de acordo com os formuladores da proposta, dado o legado histórico de constituição das redes de ensino fundamental no Brasil, não era possível "decretar" nacionalmente a municipalização, ou seja, atribuir competência exclusiva aos municípios pelo atendimento do ensino fundamental, visto que a participação de uma ou de outra rede (estadual e municipal) variava consideravelmente, dependendo do estado em questão ${ }^{1}$.

A análise da emenda constitucional do Fundef é de interesse analítico, pois ela contém elementos de efeitos imediatos - estabelecimento de patamares e obrigatoriedade de gastos - e, ao mesmo tempo, elementos que dependem da adesão dos governos subnacionais, como é o caso dos incentivos para a descentralização do ensino. 


\section{O FUNDEF E A DESCENTRALIZAÇÃO DO ENSINO FUNDAMENTAL: RACIONALIDADE ESPERADA}

A emenda constitucional do Fundef é bastante conhecida pela criação do fundo contábil que cria duas subvinculações de recursos: uma para a constituição de um fundo com recursos fiscais que passa a ser redistribuído de acordo com o número de matrículas nas redes estaduais e municipais no interior de cada estado - que deve ser obrigatoriamente gasto no ensino fundamental - e outra que obriga a um gasto mínimo com a remuneração dos profissionais do magistério (60\% desse fundo). A emenda também alterou os dispositivos constitucionais referentes aos patamares mínimos de gastos no ensino fundamental - de $50 \%$ para $60 \%$ de todas as receitas da educação -, com o objetivo de tornar prioritário o gasto nesse nível de ensino e, ao mesmo tempo, mais transparente o gasto ali realizado ${ }^{2}$.

Essas são medidas de efeito imediato: após a aprovação legislativa, alteram os patamares de gastos para todos os governos subnacionais. Estimativas apresentadas por Castro e Duarte (2008:21), por exemplo, mostram que o gasto no ensino fundamental público passou de $54 \%$ do gasto total em educação em 1995 (antes da aprovação do Fundef) para cerca de $60 \%$ em 2005, o que é coerente com os objetivos do Fundef de aumentar os gastos dos governos subnacionais com o ensino obrigatório. Dados do Tribunal de Contas do Estado de São Paulo (Diário Oficial do Poder Legislativo, 2006) também revelam os efeitos imediatos e universais desse tipo de medida: em 2005, do total de 645 municípios do Estado de São Paulo, apenas dezenove não haviam aplicado o mínimo exigido pelo Fundef no ensino fundamental (15\% das receitas de impostos e transferências). Note-se que, entre esses poucos municípios, estão incluídos aqueles com liminares da justiça suspendendo a aplicação das regras do Fundef (como Diadema e Rio Grande da Serra) ${ }^{3}$ e outros que ficaram aquém por algumas casas decimais, como Igarapava (gasto de $14,87 \%)$, Porto Ferreira $(14,71 \%)$ ou Campos do Jordão $(14,16 \%)$, sugerindo problemas de gestão e de planejamento do gasto. De forma similar, as informações compiladas pelo Tribunal de Contas do Estado de Mato Grosso confirmam a excepcionalidade do não cumprimento das regras de gasto mínimo: apenas dois municípios não haviam aplicado o mínimo de $15 \%$ no ensino fundamental em 2005, em um total de 141 municípios (TCE/MT, 2008). São, realmente, casos muito isolados. 


\section{Sandra Gomes}

Por outro lado, um dos efeitos esperados da aprovação do fundo contábil instituído pelo Fundef era o crescimento da municipalização do ensino fundamental, o que de fato ocorreu. E quais eram os efeitos esperados do Fundef que, como consequência, fariam com que os municípios ampliassem a oferta do ensino fundamental? Para responder a essa questão, é preciso compreender a mecânica do fundo contábil.

O desenho institucional do fundo previa uma forma de retenção e de redistribuição de recursos que pode, para fins analíticos, ser dividida em quatro etapas: 1 ) retenção de valores no fundo estadual ${ }^{4}$;2) cálculo do valor médio aluno/ano em cada estado; 3 ) redistribuição de acordo com o número de matrículas feitas no ensino fundamental; e 4) complementação da União nos estados e municípios abaixo da média nacional (definida anualmente pelo governo federal).

Dessa forma, o fundo premiava os governos que já tinham como prioridade o atendimento de alunos do ensino fundamental, ao mesmo tempo que punia aqueles com baixo ou nenhum atendimento. Além disso, a emenda também previa uma "redistribuição de renda" no interior de cada estado, já que os recursos retidos pelo Fundef eram distribuídos de acordo com o número de alunos, ou seja, independentemente de quanto um governo tivesse contribuído para o fundo. Isso quer dizer que municípios de baixa arrecadação fiscal que atendiam alunos do ensino fundamental passaram a contar com um incremento de receitas. Os exemplos mais citados são os municípios do Norte e do Nordeste, que já atendiam uma proporção significativa de alunos do ensino fundamental - em comparação às redes estaduais -, mas tinham baixa disponibilidade orçamentária. Como cita João Loureiro, secretário estadual de Educação do Pará, falando do caso de Eldorado dos Carajás, o impacto da implementação do Fundef fez com que o "[...] montante de recursos [disponível para investir em educação fosse] bem superior a toda a receita tributária do município" (1999:134).

Por outro lado, a medida punia os governos que não atendiam alunos do ensino fundamental, ou atendiam muito poucos, e também aqueles que possuíam maior capacidade de arrecadação fiscal. O caso do município paulista de Paulínia é exemplar nesse sentido: mesmo que passasse a atender a totalidade dos alunos do ensino fundamental, sempre perderia recursos para o fundo, dada sua alta capacidade de arrecadação fiscal. Em outras palavras, Paulínia cofinanciava a educação de outros municípios do estado ou mesmo do governo do estado. Daí deriva 
a ideia de que tal mecanismo de redistribuição de parte dos recursos da educação promovia uma "minirreforma tributária" nos estados (Negri, 1997; Castro, 1998; 2001).

Com esse formato institucional, portanto, o argumento sustentado tanto pelos formuladores da emenda constitucional na arena federal quanto por analistas dos impactos do Fundef (Neubauer, 1999; Costa, 1998; Castro, Barreto e Corbucci, 2000; Arretche, 2005; Pinto, 2002; Rodriguez, 2001; Arelaro, 2005; Melo, 2005; Abrucio, 2005; Castro e Duarte, 2008) era de que os municípios passariam a se interessar em aumentar o atendimento do ensino fundamental com vistas ao incremento potencial de suas receitas orçamentárias ${ }^{5}$.

Assim, reafirmo que, a despeito de a emenda ser um elemento importante para explicar o crescimento da municipalização do ensino, o mecanismo explicativo do rápido crescimento nacional das matrículas no cenário nacional não pode ser atribuído exclusivamente ao Fundef. Em primeiro lugar, pela premissa de que, nos cálculos dos governos subnacionais, somente a expectativa de aumentar receitas é incorporada na equação. Tal premissa ignora que, no processo de decisão de assumir ou não novos serviços públicos, há outros fatores que entram no cálculo dos governos e que podem anular os incentivos (ou punições) estritamente fiscais, como os custos de fazer crescer e gerenciar a máquina pública, as condições das contas públicas no momento de implementação da medida, a demanda estimada pelos serviços a serem oferecidos (ou, até mesmo, os retornos eleitorais dessa decisão), entre outros. Dito de outra maneira, o ato de assumir novos serviços não vem desacompanhado de ônus ${ }^{6}$. Na verdade, a observação dos estados em que a municipalização cresceu muito sugere que havia interesse desses governos estaduais justamente em transferir o "ônus" envolvido no atendimento desse nível de ensino para seus municípios, como veremos adiante. A premissa de que os governos subnacionais incorporariam em seus cálculos apenas o incremento de receitas está exemplificada nas palavras do parlamentar José Jorge (PFL-PE), relator da PEC do Fundef na Câmara, que, nesse caso, chega a sugerir que a proposta produziria uma saudável competição por recursos entre níveis de governo: "[...] estados e municípios passam a disputar alunos" (Diário do Senado Federal, 5/4/1999).

Em segundo lugar, o Fundef, sozinho, não é suficiente para explicar a municipalização do ensino fundamental em virtude do diagnóstico 
generalizado de que sua política embutia incentivos somente para os municípios. No entanto, a análise do desenho institucional da medida revela que a regra federal não atribuía exclusivamente aos municípios a distribuição de receitas de acordo com o número de alunos matriculados no ensino fundamental. Pelo contrário, como as competências continuavam compartilhadas entre estados e municípios, com relação à obrigatoriedade de atender alunos desse nível de ensino, em tese qualquer governo subnacional poderia ter interesse em aumentar esse alunado. Apesar do discurso generalizado dos formuladores do Fundef de que a medida incentivaria a municipalização, não havia nenhum dispositivo que priorizasse o atendimento municipal. Logo, a pergunta lógica que se segue é: por que os governos de estado não se interessaram também em aumentar o atendimento de alunos do ensino fundamental e, com isso, suas receitas? Dito de outra forma: por que assistimos ao crescimento da municipalização do ensino, e não a uma "estadualização" das matrículas? Uma hipótese seria a lógica do relator da PEC do Fundef na Câmara, citada acima, ou seja, na competição por alunos, os municípios teriam superado os governos estaduais.

Da mesma forma, analistas dos efeitos do Fundef também esperavam esse resultado (Neubauer, 1999; Costa, 1998; Pinto, 2002; Rodriguez, 2001; Arelaro, 2005). Na verdade, a maioria das interpretações atribui exclusivamente ao Fundef o crescimento da municipalização do ensino (Melo, 2005; Abrucio, 2005; Arretche, 2005; Castro, Barreto e Corbucci, 2000). Contudo, como argumentei anteriormente, não havia razões lógicas para esperar que apenas os municípios passassem a se interessar em aumentar o atendimento do ensino fundamental, em uma busca desenfreada por receitas, e que não seria também do interesse de alguns governos estaduais aumentar suas receitas. Em outras palavras, deve haver outros fatores que expliquem o crescimento da municipalização, e não o da estadualização das matrículas no período pós-Fundef.

A análise da execução efetiva na provisão do ensino fundamental no período pós-Fundef revela que há significativas variações no grau de municipalização entre os estados brasileiros e que o interesse do governo estadual em aprofundar a agenda de descentralização é um importante fator explicativo dos resultados alcançados. Na próxima seção, essas questões serão exploradas empiricamente. 


\section{GRAUS DE MUNICIPALIZAÇÃO POR ESTADO DA FEDERAÇÃO: INTERESSES MUNICIPAIS OU ESTADUAIS?}

A implementação nacional do Fundef, em 1998, coincide com o rápido crescimento da municipalização do ensino fundamental no Brasil. Em 1996, uma minoria de alunos de todo o ensino fundamental público no país frequentava uma escola municipal (37\%); o restante (63\%), escolas das redes estaduais de ensino. Em 2006, ou seja, dez anos depois, tal cenário se havia invertido totalmente. Os municípios passaram a atender $60 \%$ dos alunos do país.

No entanto, quando observamos a municipalização por estados da federação, verificamos que houve uma variedade de situações, ainda que todos estivessem sujeitos aos mesmos incentivos das regras do Fundef (ver Tabela 1). Houve estados em que a participação das matrículas municipais cresceu muito em um período de dez anos (1996-2006). Por outro lado, surpreende que em alguns estados o crescimento das redes municipais tenha sido modesto.

Os incentivos do Fundef não geraram um padrão similar de municipalização, o que sugere que há outros elementos, no âmbito dos estados, que explicam a variação dos graus de municipalização. Como procuro destacar neste artigo, a principal razão dessa variação é o interesse dos governos estaduais em promover ou não a descentralização do ensino em seus territórios.

Nos estados em que se verifica maior crescimento, há programas de municipalização do ensino com incentivos adicionais ao Fundef; nos estados de menor crescimento, ao contrário, esses programas estão ausentes. Esses programas estaduais tinham em comum, como veremos a seguir, a diminuição dos custos de transição que um município teria de arcar se optasse por ampliar sua rede de ensino com base apenas nos incentivos do Fundef ${ }^{7}$. Vejamos os casos mais extremos, os de maior e os de menor grau de municipalização no período a fim de ilustrar o ponto.

O Pará - o segundo estado que mais promoveu a descentralização -, já em 1996, tinha um programa de municipalização de 1a a 4⿳亠丷a série que se aprofundou após o Fundef. De acordo com o secretário estadual de Educação de então, João Loureiro (1999), o Fundef ajudou sobretudo a concretizar o programa de municipalização do estado, que originalmente previa a transferência das séries iniciais do ensino fundamental 


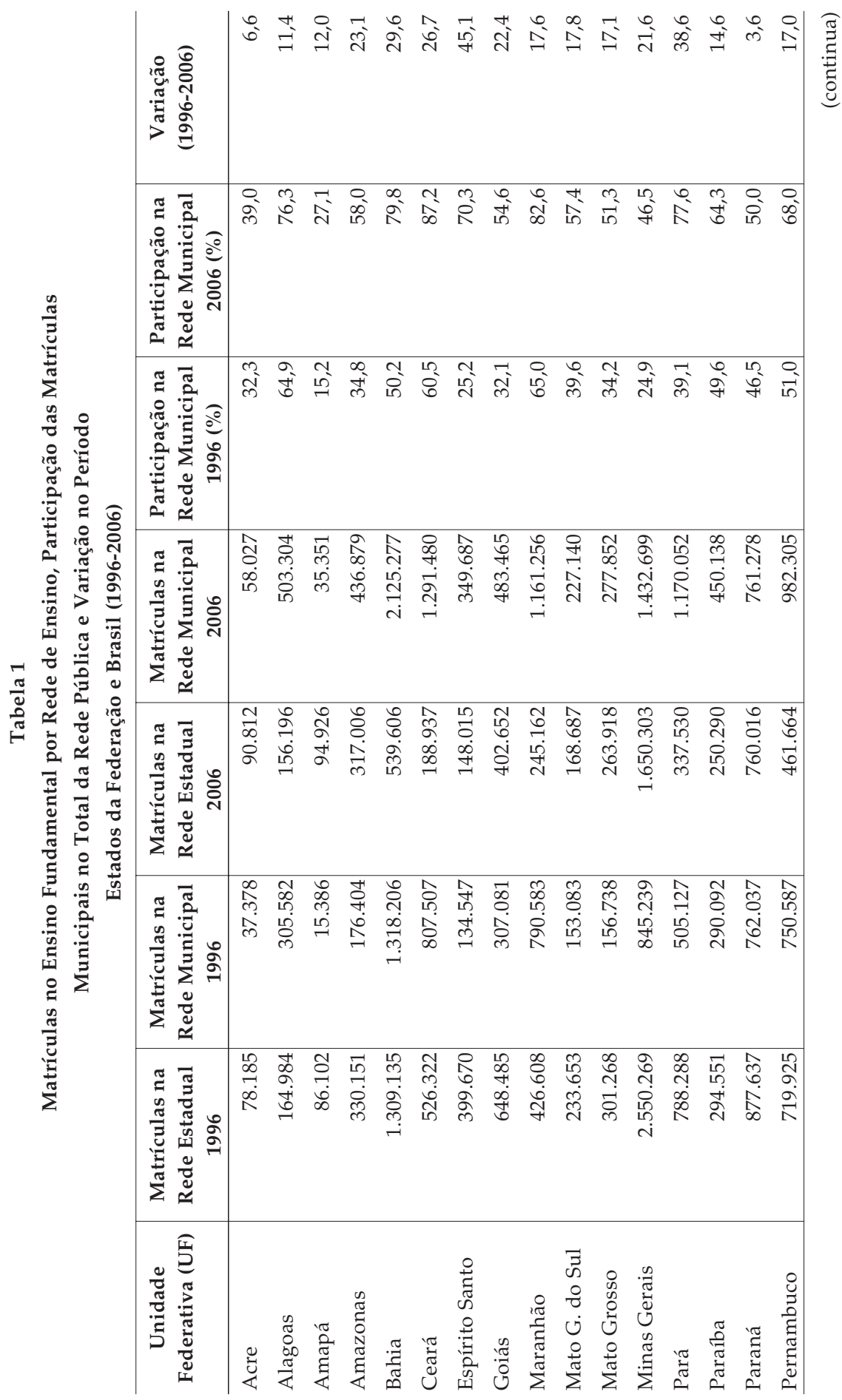


Desenho Institucional Federal e Implementação Subnacional...

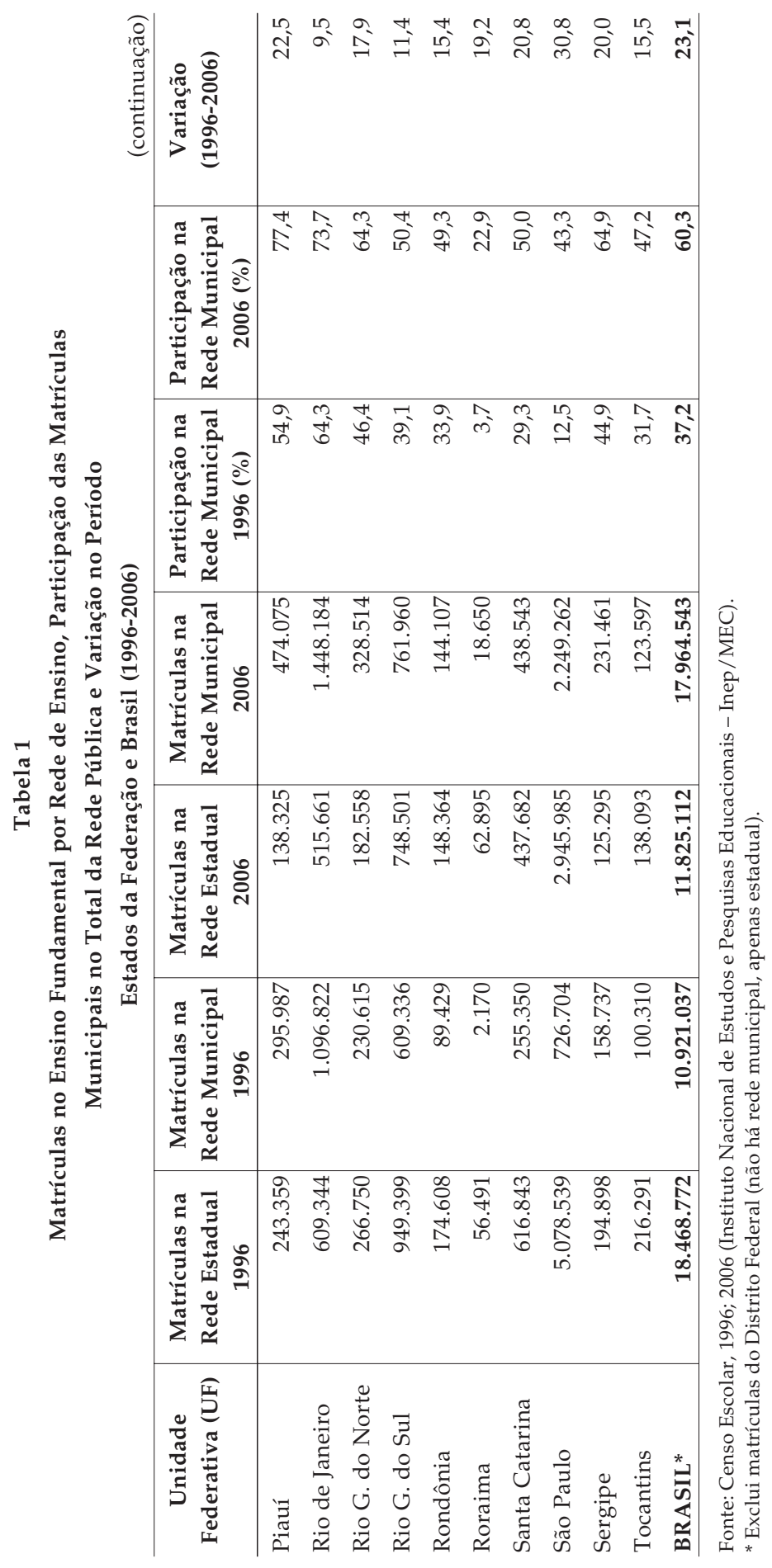


do estado para o município e, com a iminente aprovação do fundo, foi estendido às séries finais do ensino fundamental. Como a municipalização fazia parte de uma agenda já anunciada pela esfera estadual, o estado do Pará negociou com o Ministério da Educação (MEC) a antecipação da implementação para 1997. No caso desse estado, dada a alta participação das matrículas na rede estadual no início do período, a antecipação do Fundef gerou um aporte significativo de recursos para o governo do estado, financiando parte do programa estadual de municipalização. Além disso, o Pará recebeu a complementação de recursos da União por estar abaixo do valor médio nacional de gasto aluno/ano, como previsto na legislação do Fundef (Brasil, 1996; Vazquez, 2005).

A adesão de um município ao programa do Pará permitia a imediata transferência de imóveis (cessão de uso em comodato), móveis, equipamentos e pessoal da rede estadual (Loureiro, 1999). No início do programa, o estado pagava integralmente, por um período determinado, os salários do pessoal afastado dos municípios, como professores e diretores transferidos. Além disso, como a distribuição dos recursos do Fundef se baseava no número de alunos divulgado anualmente no Censo Escolar, organizado pelo Inep/MEC, o incremento de matrículas que um município tivesse feito em um determinado ano só seria computado no Censo Escolar do ano seguinte, e só então esse município passaria a receber os recursos atrelados ao número de matrículas, como determinava o Fundef. Dependendo do momento em que isso ocorresse, um município poderia, em tese, ficar quase um ano à espera do retorno do investimento feito. Contudo, se o município assinasse um termo de convênio estabelecendo com o governo do estado a transferência de escolas e de alunos, não precisaria esperar até a divulgação do próximo Censo Escolar para receber os recursos do Fundef, uma vez que a Secretaria Estadual de Educação se comprometia a repassar os valores dos alunos "municipalizados", embora estes ainda fossem registrados formalmente no Censo Escolar como alunos da rede estadual. Esse incentivo, previsto na própria legislação do Fundef, foi utilizado por todos os governos estaduais que tinham programas de incentivo à descentralização.

Como se vê, o governo do Estado do Pará criou uma série de incentivos extras para estimular a adesão de seus municípios ao programa de descentralização, o que gerou uma rápida municipalização. Em 1997, a participação da rede municipal era de $40 \%$, e um ano depois passou 
para $60 \%$. Ademais, como a política do governo estadual do Pará arcava com os custos de investimento e custeio (construção de prédios, mobiliário e contratação inicial de pessoal), que poderiam ser impeditivos (e demorados) para alguns municípios, a implementação rápida de uma rede municipal tornou-se viável em curto prazo.

Esse é o caso também do Estado do Ceará - o quinto que mais avançou a municipalização -, que tinha uma política de descentralização do ensino anterior à aprovação do Fundef. O objetivo do programa era transferir integralmente aos municípios todas as séries do ensino fundamental para que a rede estadual priorizasse o atendimento de alunos do ensino médio (Naspolini, 1999). De forma muito similar à descrita para o Estado do Pará, o estabelecimento de convênios de transferência com as prefeituras incluía uma série de benefícios adicionais ao Fundef, além de assistência técnica e pedagógica. No entanto, diferentemente do Pará, no Ceará o atendimento da rede estadual era minoritário no momento de implementação do Fundef, ou seja, o estado "perdia" receitas para seus municípios; portanto, não podia contar com esse aporte extra de recursos para financiar a descentralização. Por outro lado, o Ceará também recebeu os recursos de complementação da União.

A estratégia de descentralização adotada pelo governo do Estado de São Paulo para gerar a adesão dos municípios a seu programa de municipalização foi também o estabelecimento de termos de convênio que transferiam escolas e alunos da rede estadual para os municípios. A adesão ao programa embutia uma série de incentivos adicionais ao Fundef. Incentivos como o uso dos prédios escolares, de pessoal da rede estadual e a transferência imediata dos recursos atrelados ao Fundef facilitavam e agilizavam o aumento do atendimento municipal em comparação a uma iniciativa própria, autônoma ou isolada por parte dos municípios. Como a rede estadual de São Paulo atendia a vasta maioria dos alunos do ensino fundamental, no momento de implementação do Fundef o estado recebeu um aporte significativo de recursos - transferidos de seus municípios - que financiava o programa estadual.

Como nos casos anteriores, São Paulo já tinha, antes do Fundef, um programa de municipalização em andamento. Contudo, após a aprovação do fundo, a adesão dos municípios paulistas foi muito maior e, ao mesmo tempo, diminuiu os custos do programa estadual. Com a im- 
plementação nacional do Fundef, em 1998, os termos dos convênios são alterados, limitando-se basicamente a transferir recursos fiscais atrelados ao fundo propriamente. O programa anterior previa negociações caso a caso e recursos financeiros adicionais para municípios com baixa capacidade de gasto (Gomes, 2008).

Nesse sentido, a iniciativa do governo federal serviu aos objetivos desses três governos estaduais que já tinham em andamento programas de descentralização do ensino fundamental.

No caso do Espírito Santo - o estado que mais transferiu o atendimento -, não foram encontradas referências bibliográficas que detalhassem como foi operacionalizado o programa estadual, mas foi localizada a lei, aprovada em 1997 (Lei no 5.474), que apresenta o programa de municipalização do estado. Assim como o Estado do Pará, o Espírito Santo também negociou com o MEC a antecipação da implementação do Fundef para 1997. De acordo com a lei, caberia ao governo estadual coordenar o processo de municipalização, prestar cooperação técnica aos municípios que o aderissem, ceder pessoal do magistério para exercer funções nas redes municipais e transferir ou ceder aos municípios prédios e equipamentos escolares. Da mesma forma que nos casos anteriores, o Espírito Santo criou um programa de incentivos extras para induzir a municipalização do ensino, beneficiando-se do aporte de recursos, com a antecipação da implementação do Fundef para financiar a agenda estadual de descentralização, uma vez que o atendimento da rede estadual era majoritário. Nesse caso, assim como o Estado de São Paulo, mesmo sem nenhuma complementação extra de recursos por parte da União, uma política estadual de municipalização do ensino foi adotada.

Maria Neusa de Oliveira (2006) apresenta um levantamento dos programas estaduais criados para induzir a municipalização do ensino fundamental na Bahia. Apesar de não detalhar os termos de convênios assinados entre o estado e seus municípios, a autora destaca que estava na agenda do governo estadual "um amplo programa de modernização do estado", em consonância com as diretrizes do Ministério da Administração Federal e Reforma do Estado (Mare) de descentralização dos serviços de educação. No caso da Bahia, a rede estadual dividia o atendimento com as redes municipais no início do Fundef; portanto, o aporte de recursos extras recebidos foi menor que nos casos do Pará, São Paulo e Espírito Santo, mas maior que no caso do Ceará. Por 
outro lado, assim como o Ceará, a Bahia também recebeu complementação de recursos da União por estar abaixo da média de gasto aluno/ano nacional (Vazquez, 2005).

A apresentação desses casos em que a municipalização ocorreu de forma mais intensa, acima da média nacional, demonstra a centralidade dos programas estaduais para acelerar a municipalização do ensino. Além disso, mostra que os incentivos do Fundef não geraram uma estadualização das matrículas simplesmente porque era do interesse dos governos estaduais transferir o atendimento para seus municípios. $\mathrm{O}$ elemento comum a todos os programas estaduais de municipalização é a existência de um conjunto de incentivos que diminuem os custos de transição a que um município estaria sujeito se optasse por aumentar seu atendimento com base apenas nos incentivos derivados do Fundef. Por isso, observa-se, nesses estados, um rápido crescimento da descentralização.

Vejamos rapidamente os casos no outro extremo da Tabela 1 para verificarmos se, ao contrário do que vimos até agora, podemos observar a ausência de uma agenda estadual de municipalização nos estados em que o crescimento da municipalização foi menos intenso no período pós-Fundef.

O Estado do Paraná foi o que, depois do Fundef, menos avançou na municipalização do ensino fundamental. Seu governo já havia implementado um programa bem-sucedido de municipalização das séries iniciais do ensino fundamental, antes do Fundef, utilizando termos de parcerias que previam incentivos financeiros e ações de apoio técnico e pedagógico para os municípios (Arretche, 2000; Santos, 2003) ${ }^{8}$.

Não há registros de uma política deliberada do governo do Estado do Paraná para intensificar a municipalização de todo o ensino fundamental após a aprovação do Fundef nos estudos que tratam do tema ${ }^{9}$. É possível, dessa forma, que o pequeno crescimento da municipalização reflita iniciativas autônomas de municípios que ampliaram suas redes de ensino sem a ajuda técnica e financeira do governo do estado. Se isso for verdade, poderíamos dizer que esses seriam os casos em que apenas os incentivos do Fundef agiram diretamente nos cálculos dos municípios, ou seja, estaríamos diante do estabelecimento de uma relação direta entre o governo federal e os municípios. Diferentemente do caso do Ceará, que também teve um programa relativamente bem-sucedido de municipalização do ensino fundamental anteriormente 
ao Fundef (Arretche, 2000; Naspolini, 1999), o governo do Paraná não optou por uma agenda de aprofundamento da municipalização de todo o ensino fundamental depois do Fundef. Na verdade, observa-se um ligeiro incremento das matrículas estaduais de $5^{\underline{a}}$ a $8^{\underline{a}}$ série no período pós-Fundef, ou seja, houve alguma estadualização das matrículas nas séries finais do ensino fundamental (dados não apresentados).

O que, então, difere o Paraná do restante dos estados que adotaram programas de descentralização? O patamar inicial de matrículas da rede estadual não gerava nenhum aporte de recursos significativos para financiar um programa de intensificação da municipalização, assim como não havia complementação da União prevista para esse estado. Em outras palavras, o Paraná foi fortemente penalizado com a implementação do Fundef.

O caso do Rio de Janeiro também é emblemático do papel dos governos estaduais para explicar os diferentes graus de municipalização no país. Com a implementação do Fundef, seu governo estadual teve perdas significativas de receitas, que foram transferidas para seus municípios, pois estes já tinham uma alta participação na oferta de vagas. De fato, mesmo antes do Fundef, a participação das redes municipais era uma das mais altas do país, cerca de $60 \%$.

No caso do Rio de Janeiro, o patamar inicial de matrículas e a ausência de complementação pela União não geraram recursos extras que pudessem financiar programas de aprofundamento da municipalização no estado. Ao contrário, as perdas para o estado foram tão significativas, naquele momento, que o governo estadual chegou a anunciar a necessidade de aumentar as alíquotas estaduais de ICMS para determinados produtos para compensar a perda de receitas gerada pela implementação do Fundef. Uma reportagem publicada pela Folha de $S$. Paulo (9/1/1998) informou que o governador, Marcelo Alencar, teria conseguido um empréstimo do governo federal para compensar, parcialmente, as perdas geradas no estado, o que teria permitido retornar às alíquotas originais do ICMS (ver também $O$ Estado de $S$. Paulo, $4 / 1 / 1998)^{10}$. Em 16 de dezembro de 1998, o Senado Federal aprovou norma legal permitindo que o Estado do Rio de Janeiro contratasse uma operação de crédito do Banco do Brasil para "compensação parcial de perdas de receita decorrentes da implantação do Fundo de Manutenção e Desenvolvimento do Ensino Fundamental e de Valorização do Magistério - Fundef" (Resolução no 104). 
Não há registros de iniciativas desse governo estadual para aprofundar a municipalização do ensino fundamental, ainda que ela tenha ocorrido (de $64 \%$ para $74 \%$ ). Note-se que o patamar inicial de matrículas da rede estadual no Rio de Janeiro é muito similar àquele observado para o Estado do Ceará. O Rio de Janeiro também apresentou uma pequena estadualização das matrículas de 5a a 8a série, assim como o Estado do Paraná (dados não apresentados).

No caso do Rio Grande do Sul, um dos estados que menos avançou na descentralização do ensino no período pós-Fundef, há estudos que sugerem que a municipalização verificada seria, de fato, resultado de iniciativas autônomas dos municípios (Abreu, 2003; Costa, 1998). Arretche (2000:141-142), ao analisar políticas de descentralização do ensino fundamental no período anterior ao Fundef, em vários estados do país, concluiu que, no Rio Grande do Sul, a municipalização não estava na agenda do governo estadual, porque ali se verificaria, ao contrário, um efetivo regime de colaboração entre as redes estadual e municipais. Além disso, no caso desse estado, o maior crescimento da municipalização se deu nas séries finais do ensino fundamental ( $5^{\underline{a}}$ a $8^{\underline{a}}$ série). Em 1997, antes da implementação do Fundef, os municípios desse estado atendiam cerca de $30 \%$ dos alunos de $5 \underline{a}$ a 8 a série. Já em 2004 , eles passaram a atender $41 \%$, ou seja, observa-se um crescimento de dez pontos percentuais. Com relação às séries iniciais (1a a 4⿳亠丷a série), a municipalização foi mais modesta: de $50 \%$ para $54 \%$ no mesmo período. Ainda que somente uma análise empírica dos municípios desse estado possa responder à questão, é possível levantar a hipótese de que a ausência de incentivos de um programa estadual tenha levado os municípios que já tinham uma rede de atendimento das séries iniciais a ampliar sua rede de escolas para as séries finais do ensino fundamental.

Esse levantamento dos casos de maior e de menor crescimento da municipalização parece deixar claro que o interesse dos governos estaduais em promover ou não a descentralização do ensino fundamental é um importante fator explicativo do grau de adesão dos municípios. $\mathrm{O}$ interesse dos municípios derivado exclusivamente dos incentivos do Fundef continua sendo um elemento explicativo importante, mas insuficiente, para explicar a variação da municipalização assistida no país. O quadro que se apresenta sugere o contrário: o Fundef foi um instrumento importante para os governos estaduais que tinham uma agenda de transferência desses serviços. Em outros casos, como o Paraná e, es- 
pecialmente, o Rio de Janeiro, a perda de receitas com a implementação do Fundef era tão significativa que tornou inviáveis programas estaduais de aprofundamento da descentralização.

Esse resultado não é surpreendente quando rejeitamos a premissa de que atrelar receitas a atendimento é condição suficiente para gerar uma corrida de todos os municípios para ampliarem seus serviços. Assumir novos serviços não vem desacompanhado de ônus financeiro, administrativo, de contratação de pessoal etc., e os governos sabem disso.

Em políticas dependentes de adesão, cada governo subnacional fará seu cálculo, que leva em conta, além dos incentivos da legislação, sua realidade local. No caso da municipalização do ensino, mesmo com os incentivos do Fundef, os programas estaduais mostraram-se centrais para alterar esse cálculo: ao criar incentivos extras, a adesão ao programa diminuía os custos de transição, ou seja, parte do ônus de assumir novos alunos. Essa lógica também explica por que interessaria a alguns governos estaduais abrir mão de parte de suas receitas de educação exatamente no momento em que o Fundef estava em vigor, o que, do ponto de vista da premissa de que basta atrelar atendimento a receitas, não explicaria esse comportamento. Isso porque se trata também de uma transferência dos custos de administrar uma rede de ensino. Nos cálculos de alguns desses governos de estado, as perdas de receitas atreladas ao Fundef eram certamente menores que a manutenção de suas redes de ensino. Nesses casos, o crescimento da municipalização não é explicado pelo sucesso dos municípios na competição por alunos com o governo estadual.

Além disso, dois elementos adicionais podem ajudar a explicar o interesse de alguns governos estaduais em aprofundar a descentralização do ensino fundamental naquele momento, ainda que não haja condições aqui de comprovar essas hipóteses. $\mathrm{O}$ primeiro se refere à presença de governadores alinhados ao partido que ocupava o governo federal (PSDB).

Nos cinco estados que cresceram acima da média nacional, todos com programas de municipalização do ensino, há uma presença importante de governadores do PSDB em algum dos três governos eleitos no período de 1996 a 2006. Dos quinze governadores que passaram por esses cinco estados, dez eram do PSDB e três do PFL, na Bahia. Em geral, os estados que tiveram maior presença e continuidade de governos do 
PSDB, como São Paulo, Pará e Ceará, apresentaram mais avanços na municipalização do ensino fundamental. A continuidade administrativa é apontada como um elemento importante para a completa implementação de políticas públicas (Lubambo, 2006). No outro extremo, dos nove governadores que passaram pelos três estados que menos avançaram na descentralização (discutidos acima), houve apenas um governador do PSDB (Rio de Janeiro). Contudo, como fica evidente no caso do Rio de Janeiro (com um governo do PSDB) e do Espírito Santo (com um governador do PT), a filiação partidária não é uma variável que explica por si só a adesão a essa agenda de descentralização, já que os governos fazem seus cálculos, com base em suas realidades, para decidir se vão aderir a uma agenda ou não.

Como vimos anteriormente, a implementação do Fundef trouxe impactos negativos para as finanças do Estado do Rio de Janeiro. Nesse caso, o governador não tinha interesse em criar programas adicionais de incentivo à descentralização. Com relação ao Espírito Santo, verifica-se o contrário, o governador do PT, um partido de oposição ao governo federal, optou pelo aprofundamento da agenda de descentralização em seu estado. Uma das razões que poderia explicar as escolhas desse governo coincide com o segundo elemento que poderia explicar o interesse de alguns governos estaduais em aprofundar a transferência de serviços para seus municípios, mesmo abrindo mão de parte de suas receitas de educação.

Assim como outros estados da federação, o Espírito Santo implementou um programa de ajuste fiscal, com corte de gastos públicos, que, inclusive, levou o governador a deixar o partido em setembro de 1997, com o argumento de que a bancada petista na Assembleia Legislativa fazia oposição às medidas de contenção de gastos.

Na verdade, naquele momento, todos os governos estaduais estavam sofrendo uma grave crise financeira, dado o altíssimo grau de endividamento que gerava sucessivos déficits fiscais, os quais, por sua vez, eram resultado de uma combinação de decisões na política monetária e fiscal do governo federal desde a implementação do Plano Real (Vazquez e Santos, 2006; Sátyro, 2008).

Para os propósitos deste artigo, interessa destacar que, dada essa situação precária das contas públicas nos estados e, portanto, do equilíbrio fiscal do país, o governo federal aprova a Lei no 9.496, de 1997, que oferece aos estados a oportunidade de aderir ao programa de reestrutura- 
ção e de ajuste fiscal. Como contrapartida a esse programa que refinancia as dívidas dos estados, os governos estaduais deveriam cumprir metas de reestruturação das contas públicas, que incluíam, entre outros itens, garantir o equilíbrio das despesas com o funcionalismo público (Souza, 2007). Assim, a necessidade de efetuar cortes de gastos, especialmente os de pessoal, pode ser entendida como um fator explicativo do interesse de alguns governos de estados em aumentar a transferência do "ônus" desse serviço para os municípios, que não tinham um desequilíbrio fiscal tão intenso quanto o dos governos estaduais. Nessa lógica, os incentivos que poderiam ser derivados exclusivamente da legislação do Fundef - uma corrida por receitas - são, na prática, anulados por outra regra em vigor naquele momento, que exigia um controle do gasto público nos estados.

\section{CONCLUSÕES}

Este artigo corrobora os achados dos estudos apresentados na ciência política brasileira que destacam as novas estratégias institucionais utilizadas pelo governo federal para promover políticas nacionais ou de coordenação nacional, a despeito das garantias constitucionais de independência política dos entes federados. No caso do Fundef, apesar de a emenda conter elementos que diminuíam a autonomia decisória e de alocação de recursos dos governos subnacionais, o Executivo conseguiu aprovar a medida no âmbito legislativo, mesmo se tratando de uma legislação de potencial conflito federativo.

Por outro lado, o artigo procura contribuir para os estudos da área ao reinterpretar o papel atribuído exclusivamente ao Fundef no que se refere ao crescimento da municipalização do ensino fundamental. Essencialmente, a principal proposição é que, em termos de implementação efetiva de políticas que estão a cargo dos governos subnacionais, $\mathrm{o}$ Executivo federal pode ou não gerar coordenação nacional, dependendo da natureza da medida que se deseja aprovar.

As medidas de efeito imediato são diretrizes aprovadas pelo governo federal que estipulam patamares ou obrigatoriedades de gastos, e a aprovação gera efeitos imediatos e universais. No caso do Fundef, os dispositivos que tornaram obrigatória a aplicação mínima no ensino fundamental na remuneração do magistério e também a retenção e a distribuição do fundo contábil limitaram a autonomia decisória e de gasto dos governos subnacionais com o objetivo de ensejar patamares 
nacionais. Nessas situações, a aprovação legislativa é suficiente para gerar efeitos imediatos, como os dados apresentados confirmam.

Por outro lado, as medidas que contenham incentivos para que os governos subnacionais aumentem a oferta de serviços públicos são dependentes de adesão. Assim, outros fatores, além da norma nacional, vão influenciar os cálculos dos governos na decisão de prover o serviço ou não. Em outras palavras, atrelar recursos fiscais ao aumento na provisão de serviços não é sempre condição suficiente para produzir resultados homogêneos em todas as políticas e níveis de governo. Nesse caso, a aprovação legislativa é somente um dos elementos que vão compor os cálculos dos governos.

No caso da municipalização do ensino fundamental, o Fundef certamente gerou incentivos "diretos" para que alguns municípios optassem por expandir suas redes de ensino por iniciativa própria, ou seja, sem utilizar termos de convênio com seus governos de estado. A variação que encontramos entre os graus de municipalização nos estados, porém, não é resultado apenas do interesse dos municípios em aumentar a provisão de serviços.

Um fator explicativo importante para a compreensão da rápida descentralização é também o papel indutor dos governos estaduais. Nesse caso, esses governos foram atores políticos centrais para explicar por que em alguns estados a municipalização avançou rapidamente e, em outros, ao contrário, verificou-se um crescimento pequeno ou moderado, ainda que todos estivessem sujeitos aos incentivos e punições embutidos no Fundef.

Como apresentei neste artigo, a existência de programas estaduais com incentivos adicionais à municipalização, que reduzem incertezas e os custos de transição, foi um fator determinante para explicar as decisões dos governos municipais em assumir novos encargos, como observado nos cinco estados da federação que apresentaram o maior incremento: Espírito Santo, Pará, São Paulo, Bahia e Ceará. No outro extremo, estados fortemente atingidos pela perda de receitas no momento de implementação do Fundef, como é o caso do Rio de Janeiro e do Paraná, não adotaram programas de descentralização. Nestes, o crescimento da municipalização foi modesto, incluindo mesmo um pequeno incremento na estadualização das matrículas nas séries finais do ensino fundamental. Uma das hipóteses levantadas para o interesse dos governos estaduais em transferir parte de suas receitas de educação 
aos municípios, justamente no momento de instauração do Fundef, refere-se à necessidade de ajuste fiscal pela qual os estados passavam naquele momento.

Obviamente, a mesma lógica se aplica no caso de uma análise restrita aos municípios que aderiram ou não aos programas de municipalização em seus estados: estes também levarão em conta suas realidades locais para decidir se aumentarão ou não os serviços a serem presta$\operatorname{dos}^{11}$.

As análises desenvolvidas aqui sugerem que os governos estaduais são atores que podem fazer o papel de coordenadores de políticas em seus estados, pois assim o fizeram no caso da municipalização do ensino fundamental quando isso era de seu interesse. Os governos estaduais, ainda que não sejam, necessariamente, um obstáculo à aprovação de uma norma legal na esfera federal, permanecem como atores decisivos para a implementação de políticas, haja vista o papel central desses governos para explicar os diferentes graus de descentralização observados do ensino fundamental.

O que podemos gerar de aprendizados com relação ao que esperar da política do Fundeb recentemente aprovado e implementado de forma nacional em 2008? Ainda que a amplitude da norma se tenha expandido para o conjunto da educação básica, tornando os cálculos mais complexos, é possível destacar três aspectos. Primeiramente, nem todos os governos subnacionais aumentarão suas vagas da mesma forma; não apenas porque as demandas locais serão diferentes, mas também porque em alguns casos os custos de expandir as vagas podem superar o "bônus" de receita embutido na norma federal. Em segundo lugar, com base nos resultados apresentados neste artigo, com relação aos efeitos do Fundef, podemos esperar que, nos estados em que houver o interesse do governo estadual em aprofundar a agenda de descentralização do ensino fundamental com programas de incentivo adicionais ao Fundeb, haverá maior crescimento da municipalização. Novamente, podemos esperar variações de resultados nos estados da federação. Em terceiro lugar, o Fundeb tem apenas uma medida de efeito imediato nova: a obrigação de aplicação de $60 \%$ dos recursos na remuneração do magistério, agora em toda a educação básica. Contudo, não estabelece nenhum novo patamar obrigatório de gastos no restante da educação básica - apenas permanecem as obrigações do ensino fundamental. Nesse caso, portanto, estados e municípios terão maior autonomia 
para decidir, entre os serviços educacionais de sua competência, em quais níveis e modalidades de ensino vão priorizar o atendimento.

(Recebido para publicação em setembro de 2008)

(Versão definitiva em junho de 2009)

\section{NOTAS}

1. O relator da proposta de emenda constitucional (PEC) do Fundef em plenário, deputado José Jorge (Partido da Frente Liberal - PFL-PE), faz a seguinte declaração com relação a uma emenda parlamentar para tornar o ensino fundamental de competência exclusiva dos municípios: "[...] as redes públicas estão organizadas de forma bastante diversificada e mudanças drásticas poderão gerar mais traumas que benefícios à Educação" (Diário da Câmara dos Deputados, 23/4/1996, p. 10797).

2. Chamo de receitas da educação, neste artigo, a parcela de $25 \%$ dos impostos e transferências dos governos estaduais e municipais que devem ser, obrigatoriamente, gastos em "manutenção e desenvolvimento do ensino". Antes da emenda do Fundef, a Constituição Federal determinava que 50\% das receitas da educação deveriam ser gastas no ensino fundamental e na erradicação do analfabetismo. Essa última exigência é excluída na emenda do Fundef e, assim, os 60\% de gastos obrigatórios passam a ser aplicados exclusivamente no ensino fundamental. Uma série de padronizações nos orçamentos, combinada com mecanismos de transferências automáticas dos recursos e com abertura de contas específicas, tinha como objetivo facilitar a verificação posterior da aplicação efetiva dos recursos da educação.

3. Cinco prefeituras conseguiram, na justiça, liminar para que não integrassem o Fundef e, consequentemente, não tivessem seus recursos retidos e transferidos (Recife, Diadema, Santo André, Ribeirão Pires e Rio Grande da Serra), argumentando que se tratava de uma medida inconstitucional, pois feria a autonomia de gastos garantida pela Federação brasileira (Folha de S. Paulo, 5/2/2002). Até a extinção do Fundef, em 2006, essas prefeituras não tiveram seus recursos retidos no fundo e, portanto, eles não foram redistribuídos no interior do estado.

4. No âmbito de cada estado, governos dos estados e municípios contribuíam para a formação do fundo estadual com: 15\% do Imposto sobre Circulação de Mercadorias e Serviços (ICMS), dos fundos de Participação dos Estados e dos Municípios (FPE e FPM, respectivamente), o Imposto sobre Produtos Industrializados (IPI) e a Lei Kandir (desoneração das exportações).

5. Há vários registros na mídia de então sobre a expectativa de que o Fundef gerasse municipalização. Seguem alguns recortes: 1) “A proposta do ministro é que uma parte substancial desse total [de recursos], a ser negociada com os governadores, integre o Fundo de Valorização do Professor e seja gasto exclusivamente em ensino de $1 \stackrel{\text { o }}{ }$ grau. Além disso, o programa pretende estimular a municipalização do $1^{\circ}$ grau" (Folha 


\section{Sandra Gomes}

de S. Paulo, 1ㅇ/9/1995. Cotidiano, pp. 3-4; grifo da autora); 2) “[...] O fundo tem dois objetivos: concentrar os recursos da educação no ensino de 1 o grau e aumentar o salário dos professores. O governo também quer estimular a municipalização do ensino de $1 \underline{0}$ grau por meio da distribuição de mais recursos para os municípios que mantiverem essas escolas" (Folha de S. Paulo, 2/9/1995. Brasil, pp. 1-8; grifo da autora); 3) “O presidente Fernando Henrique Cardoso deve anunciar na próxima semana a criação de um fundo para o ensino fundamental. O ministro da Educação, Paulo Renato Souza, disse ontem em Curitiba (PR) que essa é uma das ideias do governo. 'Estamos pensando na redistribuição dos recursos para quem faz o 1 음 grau'. Segund o o ministro, os recursos existentes serão 'canalizados' para a valorização e formação do professor e para incrementar a municipalização do ensino" (Folha de S. Paulo, 29/8/1995. Nacional, pp. 3-4; grifo da autora).

6. Agradeço a Fernando Limongi a observação sobre esse ponto.

7. Agradeço a Haroldo Torres a especificação dessa relação como "custos de transição".

8. "Bem-sucedido" aqui é o resultado esperado ou o aumento da transferência na oferta do serviço, pois, como registram Arretche (2000:143) e Santos (2003), o programa de municipalização levado a cabo pelo governo estadual do Paraná foi, muitas vezes, truculento, além de ter gerado ganhos menores que os prometidos aos municípios.

9. Santos (2003:277) nota que o governo do Estado do Paraná pode ter estimulado a continuidade do processo de municipalização das séries iniciais (e talvez em detrimento do avanço dos municípios nas séries finais), por meio de um incentivo negativo (e até mesmo questionável constitucionalmente), ao determinar em lei estadual que a quota-parte do salário-educação - que deve ser redistribuída aos municípios (pelo menos $50 \%$ de acordo com lei federal e o número de alunos matriculados) - só seria dirigida aos municípios que tivessem finalizado a municipalização das séries iniciais do ensino fundamental. De fato, no período pós-Fundef, a oferta de $1^{\underline{a}}$ a $4^{\underline{a}}$ série pelos municípios no Paraná atingiu quase a universalização (96\%).

10. É possível que a avaliação de Castro (1998:27) sobre as consequências do Fundef em termos de relações intergovernamentais tivesse em mente justamente o caso do Rio de Janeiro. Diz o autor que o Fundef “[...] deve gerar um impasse e forçar negociação entre dirigentes executivos estaduais mais atingidos e os dirigentes do MEC, podendo até atingir o vértice superior do governo, visando à cobertura das perdas de recursos estaduais mediante a alocação de recursos federais".

11. Agradeço à Telma Menicucci a observação sobre esse ponto. 


\section{REFERÊNCIAS BIBLIOGRÁFICAS}

ABREU, Mariza. (2003), Levantamento de Dados, Textos, Artigos etc. sobre Municipalização do Ensino, com Ênfase no Estado do Maranhão. Consultoria Legislativa da Câmara dos Deputados. Brasília, Câmara dos Deputados.

ABRUCIO, Fernando Luiz. (2005), “Coordenação Federativa no Brasil: A Experiência do Período FHC e os Desafios do Governo Lula". Revista de Sociologia e Política, vol. 24, pp. 41-67.

ALMEIDA, Maria Hermínia Tavares de e CARNEIRO, Leandro Piquet. (2003), “Liderança Local, Democracia e Políticas Públicas no Brasil”. Opinião Pública, vol. 9, no 1, pp. 124-147.

ARELARO, Lisete Regina Gomes. (2005), “O Ensino Fundamental no Brasil: Avanços, Perplexidades e Tendências". Educação e Sociedade, vol. 26, no 92, pp. 1039-1066, especial de outubro.

ARRETCHE, Marta. (2000), Estado Federativo e Politicas Sociais: Determinantes da Descentralização. Rio de Janeiro/São Paulo, Revan/Fapesp.

(2005), “Federalismo e Políticas Sociais no Brasil: Problemas de Coordenação e Autonomia". Revista São Paulo em Perspectiva, vol. 18, no 2, pp. 111-141.

. (2007), A Centralização do Estado Federativo Brasileiro. Tese de livre-docência, Departamento de Ciência Política, Universidade de São Paulo, São Paulo.

, VAZQUEZ, Daniel e GOMES, Sandra. (no prelo), “Descentralização e Autonomia: Deslocando os Termos do Debate", in A. G. Lavalle (org.), O Horizonte da Política: Questões Emergentes e Agendas de Pesquisa. São Paulo, Cosac Naify.

BRASIL. (1996), Lei no 9.424 de 24 de dezembro de 1996. Dispõe sobre o Fundo de Manutenção e Desenvolvimento do Ensino Fundamental e de Valorização do Magistério, na forma prevista no art. 60, §7ำ do Ato das Disposições Constitucionais Transitórias e Dá outras Providências. Disponível em http: / / www.planalto.gov.br. Acessado em 8 de agosto de 2003.

CASTRO, Jorge Abrahão de. (1998), “O Fundef e o seu Impacto no Financiamento do Ensino Fundamental". Textos para Discussão, no 604, Ipea, pp. 1-46.

. (2001), "Financiamento da Educação no Brasil". Em Aberto: Financiamento da Educação no Brasil, vol. 18, pp. 11-32.

BARRETO, Angela Rabelo e CORBUCCI, Paulo Roberto. (2000), “A Reestruturação das Políticas Federais para o Ensino Fundamental: Descentralização e Novos Mecanismos de Gestão". Textos para Discussão, no 745, Ipea, pp. 1-26.

CASTRO, Jorge Abrahão de e DUARTE, Bruno de Carvalho. (2008), “Descentralização da Educação Pública no Brasil: Trajetória dos Gastos e das Matrículas". Textos para Discussão, no 1352, Ipea, pp. 1-33.

COSTA, Vera Lúcia Cabral. (1998), “Descentralização da Educação no Brasil: As Reformas Recentes no Ensino Fundamental". Cadernos de Pesquisa NEPP, no 38, pp. 1-22.

GOMES, Sandra. (2008), Fatores Explicativos das Diferentes Estratégias de Municipalização do Ensino Fundamental nos Governos Subnacionais do Brasil (1997-2000). 


\section{Sandra Gomes}

Tese de doutorado em Ciência Política, Universidade de São Paulo, Faculdade de Filosofia, Letras e Ciências Humanas, São Paulo.

LACZYNSKI, Patrícia. (2004), "A Influência do Fundef no Processo de Municipalização do Ensino Fundamental no Estado de São Paulo". Cadernos Gestão Pública e Cidadania, no 38, pp. 1-32.

LIJPHART, Arend. (1999), Patterns of Democracy: Government Forms and Performance in Thirty-Six Countries. New Haven, Yale University Press.

LOUREIRO, João de Jesus P. (1999), “Descentralização, Municipalização e Fundef no Pará", in V. L. C. Costa (org.), Descentralização da Educação: Novas Formas de Coordenação e Financiamento. São Paulo, Fundap/Cortez.

LUBAMBO, Cátia Wanderley. (2006), Desempenho da Gestão Pública: Como a População Avalia o Governo em Pequenos Municípios? Recife, Fundação Joaquim Nabuco/Ministério da Educação.

MALUF, Mônica M. Boel e SOUZA, Aparecida Neri de. (1999), “Educação: Descentralização e Reformas", in CEPAM (org.), O Município no Século XXI: Cenários e Perspectivas. São Paulo, Fundação Prefeito Faria Lima, vol. 1.

MELO, Marcus André. (2005), “O Sucesso Inesperado das Reformas de Segunda Geração: Federalismo, Reformas Constitucionais e Política Social”. DADOS, vol. 48, no 4, pp. 845-889.

NASPOLINI, Antenor. (1999), “Descentralização da Educação: A Caminhada Cearense”, in V. L. C. Costa (org.), Descentralização da Educação: Novas Formas de Coordenação e Financiamento. São Paulo, Fundap/Cortez.

NEGRI, Barjas. (1997), “O Financiamento da Educação no Brasil”. Textos para Discussão, no 1, Inep, pp. 1-20.

NEUBAUER, Rose. (1999), "Descentralização da Educação no Estado de São Paulo", in V.

L. C. Costa (org.), Descentralização da Educação: Novas Formas de Coordenação e Financiamento. São Paulo, Fundap/Cortez, pp. 168-187.

OBINGER, Herbert, LIEBFRIED, Stephan e CASTLES, Francis G. (2005), Federalism and the Welfare State. Cambridge, Cambridge University Press.

OLIVEIRA, Maria Neusa de. (2006), “A Gestão Descentralizada da Educação no Estado da Bahia: A Proposta de Municipalização do Ensino Fundamental". Anais da XXIX Reunião Anual da Anped, Caxambu, Minas Gerais.

OLIVEIRA, Vanessa Elias. (2007), O Municipalismo Brasileiro e a Provisão Local de Políticas Sociais: O Caso dos Serviços de Saúde nos Municípios Paulistas. Tese de doutorado em Ciências Políticas, Faculdade de Filosofia, Letras e Ciências Humanas, Universidade de São Paulo, São Paulo.

PINTO, José Marcelino de R. (2002), “Financiamento da Educação no Brasil: Um Balanço do Governo FHC (1995-2002)". Educação e Sociedade, vol. 23, no 80, pp. 108-135.

RIBEIRO, Maria Rosa Dória. (2002), Uma Perspectiva Histórica da Descentralização da Educação. Dissertação de mestrado, Faculdade de Educação, Universidade Estadual de Campinas. 
RODRIGUEZ, Vicente. (2001), “Financiamento da Educação e Políticas Públicas: O Fundef e a Política de Descentralização". Cadernos Cedes, ano 21, no 55, pp. 42-57.

SANTOS, Jussara Maria Tavares Puglielli. (2003), “O Processo de Municipalização no Estado do Paraná". Educar, no 22, pp. 257-279.

SÁTYRO, Natália Guimarães Duarte. (2008), Política e Instituições e a Dinâmica das Políticas Sociais nos Estados Brasileiros: Uma Análise após a Redemocratização. Tese de doutorado em Ciência Política, IUPERJ, Rio de Janeiro.

SELLERS, Jeffrey M. e LIDSTRÖM, Anders. (2007), “Decentralization, Local Governments, and the Welfare State". Governance: An International Journey of Policy, Administration, and Institutions, vol. 20, no 4, pp. 609-632.

SEMEGHINI, Ulysses Cidade. (2001), "Fundef: Corrigindo Distorções Históricas". Em Aberto: Financiamento da Educação no Brasil, vol. 18, pp. 43-57.

SOUZA, Celina. (2007), "Coalizões Eleitorais e Ajuste Fiscal nos Estados Brasileiros". Revista Brasileira de Ciências Sociais, vol. 22, no 63, pp. 31-53.

SOUZA, Paulo Renato. (2005), A Revolução Gerenciada: Educação no Brasil, 1995-2002. São Paulo, Prentice Hall.

STEGARESCU, Dan. (2005), "Public Sector Decentralization: Measurement Concepts and Recent International Trends". Fiscal Studies, vol. 26, no 3, pp. 301-333.

TCE/MT (TRIBUNAL DE CONTAS DE MATO GROSSO). (2008), “Desempenho Fiscal dos Municípios". Revista TCE, no 1, pp. 23-38.

VAZQUEZ, Daniel Arias. (2005), “Desequilíbrios Regionais no Financiamento da Educação: A Política Nacional de Equidade do Fundef". Revista de Sociologia e Política, no 24, pp. 9-24.

eSANTOS, William Silva. (2006), Regras, Ideologia Partidária e Escolha dos Eleitores: Um Balanço sobre o Comportamento Fiscal dos Municípios Paulistas. Trabalho apresentado no XXX Encontro Anual da Associação Nacional de Pós-Graduação e Pesquisa em Ciências Sociais (Anpocs), Caxambu, MG, 24-28 de outubro.

WEAVER, R. Kent e ROCKMAN, Bert A. (1993), Do Institutions Matter? Washington, Brookings Institution. 


\section{Sandra Gomes}

\section{ABSTRACT \\ National Policies and Subnational Implementation: A Review of the Decentralization of Education in Brazil}

The article presents a revision of the strategies for national coordination used by the Brazilian federal government and proposes a conceptual distinction between norms dependent on subnational government's initiatives and norms that generate immediate effect. By tracking the decentralization policy of elementary schools, the study reviews the explanatory power normally attributed to one single national law (Fundef), a norm approved in 1996 which defined rules concerning the distribution and allocation of all educational revenues collected by or transferred to subnational governments. Other explanatory factors emerge as relevant to explain the outcome, especially the existence or absence of state-level programs with additional incentives to the national law.

Key words: Fundef; States and Municipalities; policy implementation

\section{RÉSUMÉ}

Politiques Nationales et Implantation Subnationale: Une Révision de la Décentralisation Après le Fundef

Dans cet article, on présente une relecture des stratégies de coordination nationale utilisées par le gouvernement fédéral brésilien et on propose une distinction conceptuelle entre normes d'effet immédiat et normes dépendantes de l'adhésion des gouvernements subnationaux. En observant la politique d'encouragement à la municipalisation de l'enseignement de base, on reconsidère le pouvoir d'explication qui est attribué exclusivement au Fundef (Fond de Maintien et Développement de l'Enseignement Fondamental et Mise en Valeur du Professorat), une politique de gestion des finances pour l'éducation approuvée en 1996. D'autres explications s'avèrent importantes dans la compréhension des résultats, en particulier l'existence ou l'absence de programmes des états avec des aides complémentaires en faveur du Fundef.

Mots-clés: Fundef; États et municipalités; implantation de politiques 